\title{
Internet gaming disorder, social network disorder and laterality: handedness relates to pathological use of social networks
}

\author{
Polyxeni Bouna-Pyrrou • Christiane Mühle • \\ Johannes Kornhuber • Bernd Lenz
}

Received: 24 September 2014/ Accepted: 27 December 2014/Published online: 10 January 2015

(c) The Author(s) 2015, corrected publication 2021. This article is published with open access at Springerlink.com

\begin{abstract}
The internet age bears new challenges that include health risks. It is agreed that excessive internet use may reach pathological levels. However, the concept of internet addiction lacks specificity and, therefore, warrants studies on its diagnostic and etiologic classification. This study was conducted to characterize the novel DSM-5 criteria for internet gaming disorder and the adapted criteria for the "social network disorder". Based on the established association of handedness and substance use disorders, we also explored whether internet use related to laterality. For this study, 3,287 volunteers participated in the online survey and gave particulars concerning their internet use in general, internet gaming and use of social networks, laterality markers (hand, foot, eye, ear, rotational preference in gymnastics, and head turning asymmetry) and health status. Of the participants, $1.1 \%$ fulfilled the criteria for internet gaming disorder, and $1.8 \%$ fulfilled the criteria for social network disorder. The applied criteria were highly correlated with the time spent on the respective internet activities $\left(p<4 \times 10^{-56}\right)$. The analyses of comorbidity and working hours support the thresholds of $5 / 9$ criteria and $\geq 30 \mathrm{~h} /$ week spent on the internet for the classification as pathological $\left(p<5 \times 10^{-2}\right)$. Moreover, we found that left-handedness related to more affirmed criteria and longer times spent on social networks $\left(p \leq 4 \times 10^{-2}\right)$. The provided criteria proved to be userfriendly, comprehensible and well accepted. The results
\end{abstract}

P. Bouna-Pyrrou and C. Mühle contributed equally to this article.

P. Bouna-Pyrrou $(\square) \cdot$ C. Mühle $\cdot$ J. Kornhuber · B. Lenz Department of Psychiatry and Psychotherapy, FriedrichAlexander University Erlangen-Nürnberg (FAU), Schwabachanlage 6-10, 91054 Erlangen, Germany e-mail: polyxeni.bouna-pyrrou@uk-erlangen.de contribute to a better understanding of pathological internet gaming and social network use and provide evidence that biological markers of substance use disorders are involved in internet addiction.

Keywords Internet addiction - Internet gaming disorder * Social network $\cdot$ Laterality $\cdot$ Handedness

\section{Introduction}

Due to the widespread availability of the internet, individuals can engage in a growing number of fascinating activities. Epidemiological studies indicate that approximately 1-2\% of the population suffers from internet addiction (Aboujaoude et al. 2006; Bakken et al. 2009; Rumpf et al. 2013; Sussman et al. 2011), but this should be interpreted cautiously because of the lack of approved criteria. Pathological internet use is associated with numerous physical and psychiatric problems, including decreased well-being and social skills (Lemmens et al. 2011), poor job performance (Young 1999), impaired sleep quality (Andreassen et al. 2012; Dworak et al. 2007; Wolniczak et al. 2013), and depressive and anxiety disorders (Carli et al. 2013; Ko et al. 2012; Morrison and Gore 2010; Spada 2014; Weinstein and Lejoyeux 2010).

In May 2013, the American Psychiatric Association (APA) included the internet gaming disorder (IGD) in the 5th edition of the diagnostic and statistical manual of mental disorders (American Psychiatric Association 2013) as a condition warranting more research. Further knowledge on the diagnostic and etiologic classification of IGD and similar potentially addictive activities is needed (Holden 2010; Petry et al. 2014). In particular, excessive use of social network sites has been suggested as another 
new type of behavioral addiction (Andreassen and Pallesen 2014; Kuss and Griffiths 2011). Griffiths (2005) proposed that addictions share common core components. Different questionnaires for the pathological use of social network sites, which were developed in recent years, have been found to overlap with the novel diagnostic criteria for IGD (Andreassen and Pallesen 2014). Thus, we decided to use the term "social network disorder" (SND; analogous to IGD in DSM-5) and adapted the nine DSM-5 criteria for IGD to the pathological use of social networks with the aim to characterize the concept of SND in comparison to IGD.

In recent years, we used various biomarkers for intrauterine sex hormone activity and found evidence that prenatal testosterone exposure modulates the risk for alcohol use (Kornhuber et al. 2011; Lenz et al. 2012) and video gaming disorders (Kornhuber et al. 2013). These findings motivated us to follow the early sex hormone model of addictive behavior, which assumes that the intrauterine sex hormone priming of the cerebral reward system predisposes individuals to the development of addictive disorders. Cerebral lateralization is also a biomarker for prenatal androgen load (Cohen-Bendahan et al. 2005; Geschwind and Galaburda 1985; Witelson 1985), and its proxy handedness has been repeatedly linked to substance use and addictive behavior. Denny showed that left-handers drink more alcohol than do right-handers (Denny 2011), and many studies consistently demonstrate that alcohol-addicted patients are more often left-handed than are healthy persons (Harburg 1981; London et al. 1985; McNamara et al. 1994; Nasrallah et al. 1983; Sperling et al. 2000, 2010). Moreover, Preti et al. (2012) reported that lefthanders experiment more often with heroin, ecstasy and hallucinogens than non-left-handers.

Here, we set two objectives to promote the diagnostic and etiologic characterization of pathological internet use. First, we employed the novel DSM-5 criteria for the IGD and the adapted criteria for SND to evaluate their applicability and their relation to time spent on the specific activities, psychiatric co-morbidities and life style using an online survey. Second, we explored whether these criteria and leisure time use of the internet in general, of internet games and of social networks were related to laterality (handedness, footedness, eyedness, earedness, rotational preference in gymnastics, and head-turning asymmetry).

\section{Methods}

Study sample

This study was conducted in accordance with the principles expressed in the 6th revision of the Declaration of Helsinki,
Seoul 2008 and was approved by the Ethics Committee of the Friedrich-Alexander University Erlangen-Nürnberg (FAU). Interested parties were motivated to participate by the chance to win Amazon gift cards in a prize draw. Between October 2013 and March 2014, 3,287 volunteers started the 20-min standardized online survey published on the online platform SoSci Survey (www.soscisurvey.de). Of these, 1,441 participants were recruited from the SoSci Panel (Leiner 2014), and 1,846 were attracted through e-mail, social networks and public postings. The participants were excluded from analysis if they stated that they earn their living with internet gaming or were shown to have answered dishonestly, or if the data set failed to meet the SoSci quality score "DEGRADE" of at most 200 as a combined normalized indicator for missing answers and too rapid completion. Altogether, 2,595 data sets included the criteria for IGD, and 2,565 data sets the SND criteria, of which at least 2,506 covered the time spent on the respective activities.

\section{Measurements}

\section{Health status}

The participants were asked about their subjective health status on a 5-point scale (excellent, very good, good, moderate, poor), their number of medical and psychological consultations during the previous 12 months due to somatic or psychiatric disorders, and the amount of time that they had spent on sports activity and sleeping. Alcohol use was assessed using the CAGE test (Ewing 1984). Regarding smoking behavior, we divided the participants into smokers, non-smokers and ex-smokers.

\section{Internet use}

Use of the internet in general was assessed by the Compulsive Internet Use Scale [CIUS, (Meerkerk et al. 2009), German version (Wartberg et al. 2014)], which offers a valid measurement of internet use and strongly correlates with the weekly duration of private internet use (Gürtler et al. 2014). Regarding IGD, we used the novel DSM-5 criteria (American Psychiatric Association 2013; Rehbein et al. 2013) to create a German questionnaire (Table 2). Affirmative answers to the nine dichotomous items (yes/ no) were summed to a total score. Analogous to the nine proposed criteria for IGD, we designed a German questionnaire for the pathological use of social networks (Table 2), which was defined as chatting and mailing via social networks (e.g., Facebook, twitter, WhatsApp, Hangouts and other messenger services). The participants stated their average time spent on internet games or social networks during the previous 12 months. Then, they were 
asked to bring the two weeks during which they had used the internet the most during the preceding year to mind and report their maximum time spent on internet gaming or social networks.

\section{Laterality}

We applied the Waterloo Handedness QuestionnaireRevised (WHQ-R, 36 items) and the Waterloo Footedness Questionnaire-Revised (WFQ-R, 18 items) (Elias et al. 1998) translated into German. Eye and ear preference were measured by three and four questions from the lateral preference inventory (Coren 1993) in a Germanmodified version (Büsch 2009). We omitted the question concerning the preferred eye to look through the eyepiece of a rifle because it depends on handedness. In addition, ocular dominance was assessed by three repetitions of the Miles test (Miles 1928). Two elements of rotational preference in gymnastics were asked: the direction of rotation in a straight jump with a half turn and the preferred hand placed on the ground to start a cartwheel (Heinen 2012). To determine the head-turning asymmetry, we asked the participants which side they turned their head to when kissing a person on the lips (Güntürkün 2003). For all markers, we used 5-point scale answers that ranged from -2 to 2 (always left, usually left, equal, usually right and, always right; see Online Resource for the German questionnaires).

Data processing and statistical analysis

\section{Characterization of the DSM-5 criteria for IGD and the adapted SND criteria}

Group comparisons were performed using the MannWhitney $U$ and Kruskal-Wallis tests. We applied twosided Spearman's tests to evaluate the basal bivariate correlations and $\chi^{2}$ tests for differences in the frequencies. The two-tailed Fisher's exact test was used if at least one cell failed to reach an expected value of five observations. To confirm the findings, we used multivariate (MANCOVA) and univariate analysis of covariance (ANCOVA), and these were corrected for potential confounding factors [sex, smoking status, educational status (fixed factors), age, drinking status, and body mass index (BMI) (covariates)]. The Kuder-Richardson Formula 20 (KR-20) coefficient was calculated to estimate the internal consistency reliability. Receiver Operating Characteristic (ROC) and Youden's J statistic $(J=$ sensitivity + specificity -1 ) were applied to evaluate the thresholds of the time spent on the respective internet activities to discriminate the affected from the healthy individuals (Akobeng 2007).

\section{Laterality and pathological internet use}

In the exploratory step, we analyzed the effects of all laterality markers on the CIUS score, the number of affirmed IGD and SND criteria and the average and maximum time spent on the respective leisure time activities in a discovery subsample of 790 individuals who had given full particulars (MANCOVA including confounding factors). Afterward, we tested whether the initial finding could also be found in an increased cohort of 2,330 individuals. Finally, we investigated whether handedness also predicted that the participants used social networks $\geq 30 \mathrm{~h} /$ week (ANCOVA). $P<5 \times 10^{-2}$ was considered statistically significant. The continuous variables with a significant deviation from the normal distribution (Kolmogorov-Smirnov test) were transformed into ranks (skewness and excess kurtosis between -1.6 and 1.9) prior to their use in parametric statistics (Conover and Iman 1981). The data were analyzed using IBM SPSS statistics Version 21 for Windows (SPSS Inc., Chicago, IL, USA) and Graph Pad Prism 5 (Graph Pad Software Inc., San Diego, CA, USA).

\section{Results}

Characterization of the DSM-5 criteria for IGD and the adapted SND criteria

The male and female participants differed significantly in several demographic parameters (Table 1) and were, therefore, analyzed independently whenever indicated.

The participants reported no major problems in comprehending and answering the DSM-5 criteria for IGD or the adapted SND criteria. The KR-20 coefficients associated with the DSM-5 criteria for IGD were .716 ( 9.669 , o .743 ), and those associated with the SND criteria were .666 ( 9.678 , o .631). For a better understanding of the two concepts, we investigated the IGD- and SND-specific patterns of affirmed criteria in our cohort. The female participants affirmed all of the SND items more often than the male participants did, and the converse was true for all of the IGD items. Moreover, the women affirmed each SND criteria significantly more often than the equivalent IGD criteria. This pattern was inconsistent in the males. With regard to single items, we found further interesting similarities and differences between IGD, SND, females and males. Independently for the whole cohort as well as for the female and male subsample, IGD and SND have in common that "loss of control" was among the two most frequently affirmed criteria; whereas "jeopardy or loss of a significant relationship" was among the two least often affirmed criteria. To identify gender dimorphisms, we analyzed sex differences $\left(\Delta_{+}-{ }_{\delta}\right)$ regarding the percentage 
Table 1 Demographic characterization

\begin{tabular}{|c|c|c|c|c|}
\hline & 우 $(n=1,524)$ & $\hat{\jmath}(n=941)$ & Data sets $(\%)$ & $p$ value \\
\hline Age $(\text { years })^{b}$ & $27(23 / 39)^{\mathrm{a}}$ & $30(24 / 43)^{\mathrm{a}}$ & $100 \%$ & $5 \times 10^{-5}$ \\
\hline Time spent on paid work (hours/week) & $16(0 / 39)^{\mathrm{a}}$ & $20(0 / 40)^{\mathrm{a}}$ & $67 \%$ & $8 \times 10^{-4}$ \\
\hline Body weight $(\mathrm{kg})$ & $64(58 / 74)^{\mathrm{a}}$ & $80(72 / 90)^{\mathrm{a}}$ & $97 \%$ & $<10^{-99}$ \\
\hline Body height $(\mathrm{cm})$ & $168(164 / 172)^{\mathrm{a}}$ & $180(176 / 185)^{\mathrm{a}}$ & $97 \%$ & $<10^{-99}$ \\
\hline $\operatorname{BMI}\left(\mathrm{kg} / \mathrm{m}^{2}\right)$ & $22.6(20.5 / 26.0)^{\mathrm{a}}$ & $24.3(22.1 / 27.5)^{\mathrm{a}}$ & $97 \%$ & $6 \times 10^{-22}$ \\
\hline \multicolumn{5}{|l|}{ Civil status } \\
\hline Living in a partnership & $65.0 \%$ & $57.8 \%$ & $97 \%$ & $4 \times 10^{-4}$ \\
\hline Married & $23.9 \%$ & $27.3 \%$ & $92 \%$ & $7 \times 10^{-2}$ \\
\hline Divorced & $7.0 \%$ & $6.0 \%$ & $86 \%$ & $4 \times 10^{-1}$ \\
\hline Level of education & & & $97 \%$ & $5 \times 10^{-3}$ \\
\hline No graduation & $3.6 \%$ & $2.3 \%$ & & \\
\hline Lower secondary schooling & $0.3 \%$ & $1.4 \%$ & & \\
\hline Secondary schooling & $12.9 \%$ & $11.7 \%$ & & \\
\hline Higher educational level & $83.2 \%$ & $84.6 \%$ & & \\
\hline Smoking status & & & $99 \%$ & \\
\hline Smoker & $14.3 \%$ & $16.8 \%$ & & $1 \times 10^{-2}$ \\
\hline Non-smoker & $71.5 \%$ & $65.8 \%$ & & \\
\hline Ex-smoker & $14.3 \%$ & $17.3 \%$ & & \\
\hline
\end{tabular}

The $p$-values show the results from the Mann-Whitney $U$ and $\chi^{2}$ tests

$B M I$ body mass index

${ }^{a}$ Median, 25/75\%; $p<5 \times 10^{-2}$ in bold print

b Obligatory answer

Table 2 Frequency of affirmed IGD and SND criteria for the whole sample ("WS") and divided by sex

\begin{tabular}{|c|c|c|c|c|c|c|c|c|c|c|c|}
\hline & \multicolumn{6}{|c|}{ Percent of affirmed criteria } & \multicolumn{5}{|l|}{$p$ values } \\
\hline & \multicolumn{3}{|c|}{ IGD $(\%)$} & \multicolumn{3}{|c|}{ SND $(\%)$} & \multicolumn{2}{|l|}{ † vs. ठิ } & \multicolumn{3}{|c|}{ IGD vs. SND } \\
\hline & WS & 우 & $\widehat{0}$ & WS & 우 & $\hat{\jmath}$ & IGD & SND & WS & q & $\hat{\jmath}$ \\
\hline Preoccupation & 2.5 & 1.5 & 4.0 & 11.7 & 12.7 & 10.2 & $9 \times 10^{-5}$ & $6 \times 10^{-2}$ & $6 \times 10^{-3}$ & $2 \times 10^{-2}$ & $1 \times 10^{-1}$ \\
\hline Withdrawal symptoms & 0.8 & 0.7 & 0.9 & 5.0 & 6.0 & 3.3 & $7 \times 10^{-1}$ & $2 \times 10^{-3}$ & $2 \times 10^{-4}$ & $2 \times 10^{-4}$ & $2 \times 10^{-1}$ \\
\hline Tolerance & 4.7 & 3.5 & 6.8 & 11.0 & 12.5 & 8.7 & $2 \times 10^{-4}$ & $4 \times 10^{-3}$ & $8 \times 10^{-5}$ & $1 \times 10^{-8}$ & $8 \times 10^{-1}$ \\
\hline Loss of control & 7.6 & 6.4 & 9.5 & 13.0 & 14.2 & 11.1 & $6 \times 10^{-3}$ & $2 \times 10^{-2}$ & $4 \times 10^{-20}$ & $7 \times 10^{-13}$ & $1 \times 10^{-9}$ \\
\hline $\begin{array}{l}\text { Continued use despite adverse } \\
\text { consequences }\end{array}$ & 5.2 & 3.3 & 8.2 & 10.6 & 11.2 & 9.7 & $1 \times 10^{-7}$ & $2 \times 10^{-1}$ & $6 \times 10^{-14}$ & $4 \times 10^{-12}$ & $2 \times 10^{-5}$ \\
\hline Loss of interest in previous hobbies & 1.8 & 0.9 & 3.4 & 1.9 & 2.2 & 1.5 & $4 \times 10^{-6}$ & $2 \times 10^{-1}$ & $1 \times 10^{-6}$ & $4 \times 10^{-6}$ & $1 \times 10^{-2}$ \\
\hline $\begin{array}{l}\text { Use of internet to escape or relieve a } \\
\text { negative mood }\end{array}$ & 8.6 & 7.4 & 10.6 & 12.8 & 15.3 & 8.8 & $6 \times 10^{-3}$ & $3 \times 10^{-6}$ & $1 \times 10^{-22}$ & $2 \times 10^{-23}$ & $1 \times 10^{-4}$ \\
\hline Dissimulation & 1.8 & 1.0 & 3.2 & 1.5 & 1.7 & 1.2 & $7 \times 10^{-5}$ & $3 \times 10^{-1}$ & $3 \times 10^{-2}$ & $2 \times 10^{-3}$ & 1 \\
\hline $\begin{array}{l}\text { Jeopardy or loss of a significant } \\
\text { relationship }\end{array}$ & 1.1 & 0.5 & 2.1 & 1.1 & 1.3 & 0.9 & $3 \times 10^{-4}$ & $3 \times 10^{-1}$ & $4 \times 10^{-2}$ & $4 \times 10^{-3}$ & 1 \\
\hline
\end{tabular}

The $p$ values show the results from the $\chi^{2}$ or Fisher's exact tests. $p<5 \times 10^{-2}$ in bold print

WS whole sample

of affirmed IGD and SND criteria (Table 2). The three greatest differences for IGD were that males affirmed "continued use despite adverse consequences" $\left(\Delta_{+}-\hat{\jmath}=\right.$
$-4.8 \%)$, "tolerance" $(-3.3 \%)$ and "use of internet to escape or relieve a negative mood" (-3.2\%) more often than females and for SND that females affirmed "use of 
internet to escape or relieve a negative mood" (6.5\%), "tolerance" (3.8\%) and "loss of control" (3.2\%) more often than males. Finally, we calculated the differences of the aforementioned gender dimorphisms between IGD and $\operatorname{SND}\left[=\operatorname{IGD}\left(\Delta_{+}-{ }_{0}\right)-\operatorname{SND}\left(\Delta_{\varphi}-{ }_{0}\right)\right]$ and found the three greatest differences for "use of internet to escape or relieve a negative mood" $(-9.7 \%)$, "tolerance" $(-7.1 \%)$ and "continued use despite adverse consequences" (-6.3\%). This illustrates that those criteria are predominantly related to social network sites in females and to internet games in males (Table 2).

As expected, there were strong positive Spearman's correlations between the number of affirmed IGD and SND criteria and the time spent on internet gaming or social networks, the CIUS score and age for both sexes (Table 3).

These findings were confirmed by multivariate analyses including potential confounders. The numbers of affirmed IGD and SND criteria were associated with the CIUS score and the time spent on internet gaming (MANCOVA, $n=2,253: F=505, p<10^{-99}$, Wilk's $\Lambda=.595$, partial $\left.\eta^{2}=.405\right)$ and social networks $(n=2,227: F=231$, $p<10^{-99}$, Wilk's $\Lambda=.761$, partial $\eta^{2}=.239$ ). More specifically, the number of IGD criteria related to the CIUS score $\left(F=177, p=7 \times 10^{-39}\right.$, partial $\left.\eta^{2}=.074\right)$ and the average $\left(F=1,290, p<10^{-99}\right.$, partial $\left.\eta^{2}=.367\right)$ and maximum $\left(F=1,276, p<10^{-99}\right.$, partial $\left.\eta^{2}=.367\right)$ time spent on internet games. The male participants reported significantly longer maximum time spent on internet games compared with the females. Moreover, the proposed SND criteria related to the CIUS score $(F=277$, $p=1 \times 10^{-58}$, partial $\left.\eta^{2}=.112\right)$ and the average $\left(F=418, p=4 \times 10^{-85}\right.$, partial $\left.\eta^{2}=.159\right)$ and maximum $\left(F=427, p=8 \times 10^{-87}\right.$, partial $\left.\eta^{2}=.162\right)$ time spent on social networks. Here, we found significantly lower CIUS scores in females than in males and in exsmoker than in smoker participants.

We then subdivided the participants into groups depending on the number of affirmed IGD and SND criteria (" 0 ", "1-4", "5-9") and found significant differences (Fig. 1). The participants who affirmed 5-9 criteria reported that they spent a median maximum time on internet games of $8.0 \mathrm{~h} /$ day $(25 / 75 \%$ percentiles 5.0/12.0) and a median maximum time on social networks of $5.0 \mathrm{~h} /$ day (3.6/7.8).

Altogether, $1.1 \%\left[\left(10++17 \delta^{\Uparrow}\right) / 2,465\right]$ of the participants suffered from IGD, and $1.8 \%[(35 \propto+10 \hat{\jmath}) / 2,465]$ suffered from SND. In comparison with the females, the males showed an increased prevalence of IGD ( $\widehat{0} 1.8 \mathrm{vs}$. 우 $0.7 \%, p=8 \times 10^{-3}$ ) and a decreased prevalence of SND (o) 1.1 vs. ㅇ $2.3 \%, p=3 \times 10^{-2}$ ). The Youden's index for IGD was maximal at $3.75 \mathrm{~h} /$ day (area under the curve [AUC] .943; sensitivity .926; specificity 0.844, $p=2 \times 10^{-15}$ ) and for SND at $2.75 \mathrm{~h} /$ day (AUC .830;





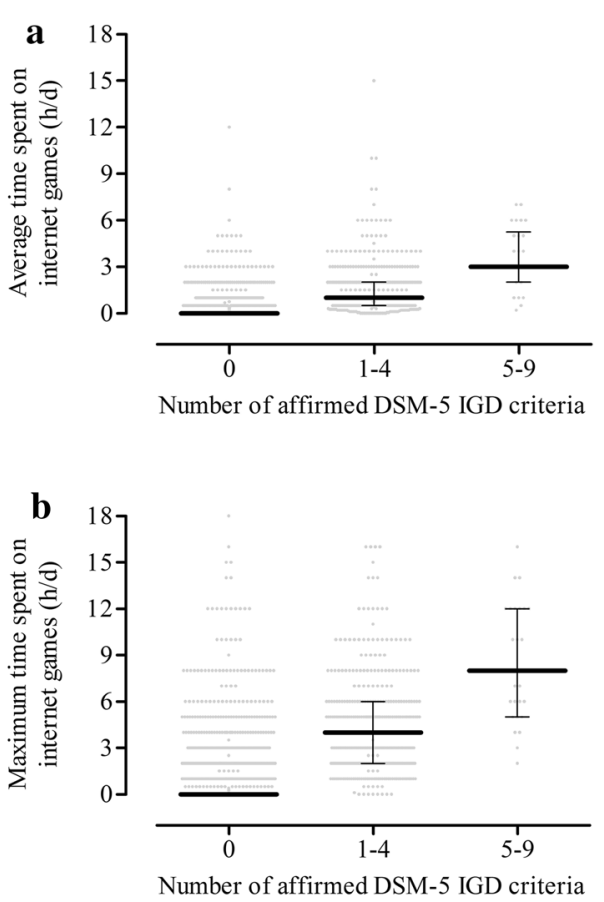

Fig. 1 Relationship between the DSM-5 and the adapted criteria for IGD and SND and the time invested on internet gaming or social networks The subgroups based on the number of affirmed IGD or SND criteria differed in the time spent on internet games $[\mathbf{a}, \mathbf{b}$ average, Kruskal-Wallis test: $\chi^{2}=972, p<10^{-99}$; maximum, Kruskal-Wallis test: $\chi^{2}=963, p<10^{-99}$; significant post hoc results

sensitivity .909 ; specificity $0.612, p=6 \times 10^{-14}$ ). Overall, $61.4 \%\left[\left(1,012 \propto+501 \varsigma^{\uparrow}\right) / 2,465\right]$ of the participants denied the use of internet games during the preceding year, and $17.4 \%\left[\left(241 \%+189{ }^{3}\right) / 2,465\right]$ denied the use of social networks.

\section{IGD, SND and health status}

We were interested in the impact of pathological internet use on an individual's life and used two thresholds for a classification of pathological: (1) the number of affirmed criteria ("0-4" vs. "5-9") and (2) the time spent on the internet (" $<30$ " vs. " $\geq 30 \mathrm{~h} /$ week") based on our ROC curves [sensitivity/specificity, $\operatorname{IGD}_{(31.5 \mathrm{~h} / \text { week })} .852 / .884$, $\left.\mathrm{SND}_{(29.75 \mathrm{~h} / \text { week })} .636 / .843\right)$ and the cutoffs suggested by Rumpf et al. (2013). The analyses revealed that the participants who affirmed $\geq 5$ of the IGD or SND criteria suffered significantly more often from depression, eating disorders and burnout. Spending $\geq 30 \mathrm{~h} /$ week on social networks related to increased risks for depression, obsessive-compulsive disorders and eating disorders (Table 4). Sex-specific analyses revealed additional significant associations. The females who affirmed $\geq 5$ criteria were at increased risks of depression [odds ratio (OR) IGD 4.9, $p=2 \times 10^{-2} ;$ SND 3.2, $p=5 \times 10^{-3}$ ], eating disorders


(Dunn's tests) for "0" vs. "1-4" and "0" vs. "5-9"] and social networks [c, d average, Kruskal-Wallis test: $\chi^{2}=525, p<10^{-99}$; maximum, Kruskal-Wallis test: $\chi^{2}=559, p<10^{-99}$; significant post hoc results (Dunn's tests) for "0" vs. "1-4", "0" vs. "5-9" and "1-4" vs. "5-9"]. The graphs show the medians and the 25/75 percentiles

(OR SND 5.8, $p=2 \times 10^{-2}$ ), and burnout (OR SND 4.0, $1 \times 10^{-2}$ ); social network use for $\geq 30 \mathrm{~h} /$ week related to increased risks for depression (OR 1.8, $p=2 \times 10^{-3}$ ), eating disorders (OR 2.5, $p=4 \times 10^{-2}$ ) and other psychiatric disorders (OR 2.4, $p=6 \times 10^{-4}$ ). The males who affirmed $\geq 5$ IGD criteria were at increased risks of depression (OR 4.8, $p=1 \times 10^{-2}$ ) and panic/anxiety disorder (OR 4.5, $p=4 \times 10^{-2}$ ).

Except that the participants who affirmed $\geq 5$ of the criteria for SND affirmed more of the CAGE criteria for a misuse of alcohol $\left(p=3 \times 10^{-3}\right)$, there were no further significant differences between the groups regarding CAGE scores or smoking status. With regard to the use of mental health services, a higher frequency of medical and psychological consultations during the preceding year for mental disorders was related to $\geq 5$ affirmed criteria for IGD $\left(p=3 \times 10^{-2}\right)$ and SND $\left(p=3 \times 10^{-4}\right)$. The participants who used social networks $\geq 30 \mathrm{~h} /$ week reported searching for professional help for mental disorders more frequently $\left(p=2 \times 10^{-3}\right)$. Moreover, there were no group differences in terms of the self-estimated health status, the number of doctors' visits due to somatic morbidities during the previous 12 months or the time spent on sport or sleep. Finally, we found that belonging to the risk group with $\geq 30 \mathrm{~h} /$ week spent on internet games was associated with 
Table 4 Comparison of the frequency of psychiatric disorders associated with IGD and SND

\begin{tabular}{|c|c|c|c|c|c|c|c|c|c|c|c|c|c|c|c|}
\hline & \multicolumn{7}{|l|}{ IGD } & \multicolumn{8}{|l|}{ SND } \\
\hline & \multicolumn{4}{|c|}{ Criteria 5-9 } & \multicolumn{3}{|c|}{ Time $\geq 30 \mathrm{~h} /$ week } & \multicolumn{4}{|c|}{ Criteria 5-9 } & \multicolumn{4}{|c|}{ Time $\geq 30 \mathrm{~h} /$ week } \\
\hline & $\%$ & OR & $p$ & & $\%$ & OR & $p$ & $\%$ & OR & $\mathrm{p}$ & & $\%$ & OR & $p$ & \\
\hline Depression & 33.3 & 4.3 & $1 \times 10^{-3}$ & +90 & 9.9 & 0.9 & $7 \times 10^{-1}$ & 27.3 & 3.2 & $2 \times 10^{-3}$ & 우 & 14.3 & 1.5 & $1 \times 10^{-2}$ & 7 \\
\hline Mania & 0 & - & 1 & & 0.3 & 1.2 & 1 & 0 & - & 1 & & 0.3 & 0.8 & 1 & \\
\hline $\begin{array}{l}\text { Psychosis/ } \\
\text { schizophrenia }\end{array}$ & 0 & - & 1 & & 0.3 & 1.4 & $6 \times 10^{-1}$ & 0 & - & 1 & & 0.5 & 2.5 & $3 \times 10^{-1}$ & \\
\hline Substance use disorder & 0 & - & 1 & & 0.3 & 0.4 & $7 \times 10^{-1}$ & 0 & - & 1 & & 1.0 & 1.4 & $5 \times 10^{-1}$ & \\
\hline Panic/anxiety disorder & 11.1 & 2.1 & $2 \times 10^{-1}$ & $\hat{0}$ & 7.0 & 1.3 & $3 \times 10^{-1}$ & 6.8 & 1.2 & $7 \times 10^{-1}$ & & 6.0 & 1.1 & $7 \times 10^{-1}$ & \\
\hline OCD & 3.7 & 9.2 & $1 \times 10^{-1}$ & & 0.7 & 1.6 & $6 \times 10^{-1}$ & 2.3 & 5.5 & $2 \times 10^{-1}$ & & 1.3 & 4.2 & $2 \times 10^{-2}$ & \\
\hline Eating disorder & 0 & - & 1 & & 0.7 & 0.5 & $6 \times 10^{-1}$ & 6.8 & 6.9 & $1 \times 10^{-2}$ & 우 & 2.5 & 2.8 & $2 \times 10^{-2}$ & 우 \\
\hline Burnout & 7.4 & 2.0 & $3 \times 10^{-1}$ & & 2.6 & 0.7 & $3 \times 10^{-1}$ & 13.6 & 4.2 & $6 \times 10^{-3}$ & 우 & 4.5 & 1.2 & $4 \times 10^{-1}$ & \\
\hline ADHD & 0 & - & 1 & & 0.7 & 1.0 & 1 & 2.3 & 3.7 & $3 \times 10^{-1}$ & & 0.8 & 1.2 & $7 \times 10^{-1}$ & \\
\hline Other & 7.4 & 1.8 & $3 \times 10^{-1}$ & & 2.6 & 0.6 & $1 \times 10^{-1}$ & 9.1 & 2.3 & $1 \times 10^{-1}$ & & 6.5 & 1.7 & $2 \times 10^{-2}$ & 우 \\
\hline
\end{tabular}

Table 3 shows the prevalence and odds ratios (OR) of psychiatric disorders in the participants with pathological internet use. " $O$ " and " 7 " denote significant results in the sex-specific analyses (see text for details). The $p$-values illustrate the results from the $\chi^{2}$ or Fisher's exact tests. $p<5 \times 10^{-2}$ in bold print. Missing data $<2.7 \%$

$O C D$ obsessive-compulsive disorder, $A D H D$ attention deficit hyperactivity disorder

less working hours/week $\left(p=4 \times 10^{-3}\right)$ and that spending $\geq 30 \mathrm{~h} /$ week on social networks was associated with less working hours/week $\left(p=3 \times 10^{-2}\right)$ and less months of employment during the preceding year $\left(p=1 \times 10^{-3}\right)$.

\section{Laterality and internet use}

In a first step, we explored the Spearman's correlations between the markers of laterality and internet use in a discovery sample of 532 females and 258 males, with complete data on all of the details [median $(25 / 75 \%$ percentiles): age 29 years (24/41); BMI $23 \mathrm{~kg} / \mathrm{m}^{2}$ (21/26)]. Left-handedness was associated with a longer maximum time spent on social networks ( $\rho=-.074, p=4 \times 10^{-2}$ ), and a preference for right-side kissing was associated with higher CIUS scores $\left(\rho=.078, p=3 \times 10^{-2}\right)$. Stronger left-handed females affirmed more SND criteria $(\rho=$ $-.087, p<5 \times 10^{-2}$ ) and their stronger ocular right lateralization (Miles test) was associated with higher CIUS scores $\left(\rho=.091, p=4 \times 10^{-2}\right)$. In males, lefthandedness related to a longer average $(\rho=-.150$, $p=2 \times 10^{-2}$ ) and maximum time spent on social networks $\left(\rho=-.194, p=2 \times 10^{-3}\right)$, and left-footedness related to a longer maximum time spent on internet games $\left(\rho=-.123, p<5 \times 10^{-2}\right)$. The multivariate model confirmed that-among all of the laterality markers-primary handedness related to the SND criteria $(F=8$, $p=6 \times 10^{-3}$, partial $\left.\eta^{2}=.010\right)$ and maximum time $\left(F=6, p=1 \times 10^{-2}\right.$, partial $\left.\eta^{2}=.008\right)$ spent on social networks (MANCOVA: $F=2, p=4 \times 10^{-2}$, Wilk's $\Lambda=.981$, partial $\left.\eta^{2}=.019\right)$. Footedness was also associated with the number of affirmed SND criteria $\left(F=5, p=3 \times 10^{-2}\right.$, partial $\left.\eta^{2}=.006\right)$. No other laterality marker showed any significant influence on the CIUS score, internet gaming or the use of social networks. The model was strongly influenced by age $(F=40, p=8 \times$ $10^{-48}$, Wilk's $\Lambda=.730$, partial $\left.\eta^{2}=.270\right)$, sex $(F=2$, $p=2 \times 10^{-2}$, Wilk's $\Lambda=.978$, partial $\left.\eta^{2}=.022\right)$ and the CAGE score $\left(F=7, p=2 \times 10^{-7}\right.$, Wilk's $\Lambda=.943$, partial $\left.\eta^{2}=.057\right)$.

Using an enlarged sample of 1,439 females and 891 males [median (25/75 \% percentiles): age 28 years (23/41); BMI $\left.23 \mathrm{~kg} / \mathrm{m}^{2}(21 / 26)\right]$, we found a similar association of handedness with the SND criteria $\left(F=5, p=3 \times 10^{-2}\right.$, partial $\left.\eta^{2}=.002\right)$ and the average $\left(F=6, p=1 \times 10^{-2}\right.$, partial $\left.\eta^{2}=.003\right)$ and maximum $\left(F=12, p=5 \times 10^{-4}\right.$, partial $\eta^{2}=.005$ ) time spent on social networks (MANCOVA, $F=4, p=5 \times 10^{-3}$, Wilk's $\Lambda=.994$, partial $\left.\eta^{2}=.006\right)$. As expected, this model was also strongly influenced by age $\left(F=202, p<10^{-99}\right.$, Wilk's $\Lambda=.793$, partial $\left.\eta^{2}=.207\right)$, CAGE score $\left(F=13, p=4 \times 10^{-8}\right.$, Wilk's $\Lambda=.984$, partial $\left.\eta^{2}=.016\right)$ and sex $(F=9$, $p=9 \times 10^{-6}$, Wilk's $\Lambda=.989$, partial $\left.\eta^{2}=.011\right)$. To avoid bias by psychiatric morbidities, we repeated this analysis after exclusion of participants who reported to be affected and found a similar link between handedness and use of social networks $[n(+)=1,133, n(\hat{o})=754$; MANCOVA, $F=3, p=2 \times 10^{-2}$, Wilk's $\Lambda=.995$, partial $\left.\eta^{2}=.005\right]$.

Finally, the participants who reported a maximum time spent on social networks $\geq 30 \mathrm{~h} /$ week during the previous 12 months were more strongly left-handed compared with 


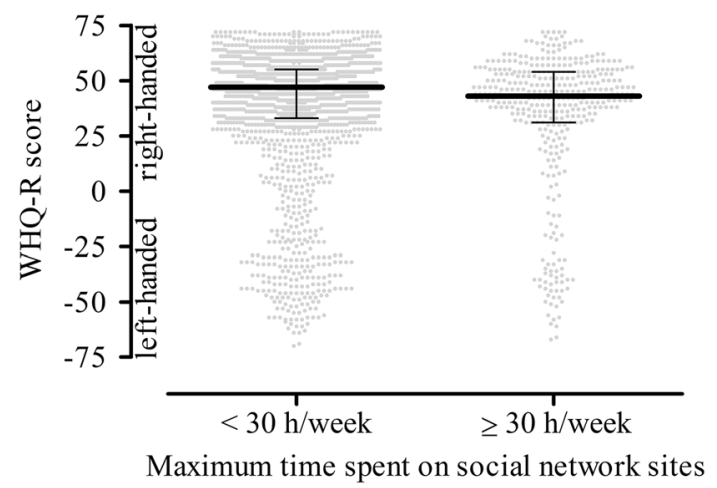

Fig. 2 Difference in handedness between the healthy and excessive users of social networks. The participants who reported spending $\geq 30 \mathrm{~h} /$ week (h/week) on social networks scored lower on the waterloo handedness questionnaire-revised (WHQ-R) and were thus more strongly left-handed than participants who stated using social networks $<30 \mathrm{~h} /$ week (Mann-Whitney $U$ test, $U=337,810$, $\left.p=3 \times 10^{-3}\right)$. The graph shows the medians and the $25 / 75$ percentiles

the never or rare social network users (ANCOVA: $F=6$, $p=1 \times 10^{-2}$, partial $\eta^{2}=.003$; Fig. 2).

\section{Discussion}

Applicability and characterization of the DSM-5 criteria for IGD and the educed SND criteria

With the inclusion of IGD in the DSM-5, the APA encouraged empirical research on the proposed IGD criteria (American Psychiatric Association 2013). The neglect of other internet activities such as chatting leads to a onesided diagnostic approach that has not been approved scientifically (Thomasius et al. 2014). Therefore, our first aim was to examine the applicability of the DSM-5 research criteria for IGD and the adapted criteria for SND. Overall, the provided criteria proved to be user-friendly and comprehensible in our study. The internal consistency reliability (KR-20 coefficient) was .716 for the DSM-5 IGD criteria and .666 for the SND criteria. The core components of addiction such as "salience, mood modification, tolerance, withdrawal, conflict and relapse" (Griffiths 2005) entail increased times of use. Accordingly, the pathological users in our study reported significantly longer times spent on the internet than did the healthy users. The strong correlations of the IGD and the SND criteria with the CIUS scores and the time spent on the respective internet activities corroborate the concept of internet use disorders. Moreover, the subgroups based on the number of affirmed criteria ("0", "1-4", "5-9") differed significantly. The cut-off value of $5 / 9$ criteria proved to be useful because the "5-9" SND group in particular reported a significantly higher time spent on social networks compared with the " 0 " and "1-4" groups. The prevalence of $1.1 \%$ for IGD and $1.8 \%$ for SND is in line with other independent conservative reports of Western countries (Aboujaoude et al. 2006; Bakken et al. 2009; Rumpf et al. 2013; Sussman et al. 2011). As expected, age and sex showed strong effects. In line with previous reports (Andreassen et al. 2012, 2013), younger age related to more affirmed IGD and SND criteria. The male participants were more likely to affirm several IGD criteria and report more time spent on internet games; the female participants affirmed SND criteria more often (Table 2). These findings agree with other studies showing that males are at greater risk to develop IGD (Batthyàny et al. 2009; Wenzel et al. 2009) and that females are jeopardized more often by SND (Durkee et al. 2012). Whether the use of the internet is pathological depends on the consequences that it carries for life. Hence, it is important to mention that the participants who were classified as pathological users (5-9 IGD, 5-9 SND criteria or $\geq 30 \mathrm{~h} /$ week spent on the respective internet activity) were significantly more likely to consult professionals for depression, obsessive-compulsive disorder, eating disorder, burnout and panic/anxiety disorder. In line with previous findings on comorbid psychiatric disorders in excessive internet users (Carli et al. 2013; Morrison and Gore 2010; Spada 2014; Weinstein and Lejoyeux 2010), our report notes that pathological internet use negatively impacts mental health. Finally, our observation that $\geq 30 \mathrm{~h} /$ week spent on internet activities relates to significantly fewer working hours/week and to fewer months of employment during the preceding year further illustrates how pathological internet use may impair an individual's life.

Laterality and internet use

The second goal of this study was to explore whether internet use in general, internet gaming and/or the use of social networks relate to the variables of cerebral lateralization. We investigated a broad range of markers (handedness, footedness, eyedness, earedness, rotational preference in gymnastics and head-turning asymmetry) and were mindful of potential confounding factors such as sex, age, smoking and drinking status, educational status and body mass index. Within a discovery sample $(n=790)$, we detected significant associations of handedness with the number of affirmed SND criteria and the time spent on social networks. This association was also found in the enlarged sample of 2,330 participants, but we acknowledge the small effect sizes (Spearman's $\rho=-.194$ to -.074 ; MANCOVA $\eta^{2}=.002-.010$ ). Moreover, those who spent $\geq 30 \mathrm{~h} /$ week on social networks were significantly more strongly left-handed. As far as we know, this is the first 
investigation that identifies left-handedness as a risk factor for pathological use of social networks. Although it remains to be specified whether handedness and prenatal testosterone correlate positively or negatively (Geschwind and Galaburda 1985; Witelson 1985), the results of this study agree with our early sex hormone model of addiction. Accordingly, a recent study reported pathological social network use to relate to impulsivity (Wu et al. 2013), which is a strongly sex-specific behavioral trait that is influenced by prenatal testosterone exposure (Wacker et al. 2013) and is linked to substance-related addictions (Lejuez et al. 2010; Potenza and de Wit 2010). Nevertheless, we found no significant association between laterality markers and internet gaming. This may be due to the relatively small number of males within the discovery sample $(n=258)$. Another reason might be that social reinforcement, which is a main factor regarding the internet's addictive potential (Morahan-Martin and Schumacher 2000), is more relevant to social networks than to internet games.

\section{Strengths and limitations}

The large cohort enabled us to control for several potentially influencing demographic variables. The anonymity of the participants reduced confounding by social stigmatization. However, the sample is not representative of the general population, and attention is advised against overgeneralization. The recruitment partly through e-mail, internet ads, social networks and the online survey entails a selection toward internet users. The investigated cohort is also characterized by a high educational level. Moreover, all of the implemented measures were self-report questionnaires, and we cannot rule out careless or wrong answers despite the application of several quality measurements. Finally, the cross-sectional study design does not allow us to estimate the test-retest reliability of the criteria or draw conclusions about causalities that underlie the development of pathological internet use.

In summary, we successfully applied and characterized the DSM-5 research criteria for IGD and the adapted criteria for SND. Their associations with comorbid psychiatric disorders demand stronger attention to pathological use of internet games and social networks in clinical practice. Moreover, we found that the use of social networks is related to handedness, which is in line with our early sex hormone model of addiction and supports the classification of pathological internet use as an addictive disorder.

Supplementary Information The online version contains supplementary material available at https://doi.org/10.1007/s00702-014-1361-5.

Acknowledgments This work was supported by intramural grants from the University Hospital of the Friedrich-Alexander University Erlangen-Nürnberg (FAU). We would like to thank the participants and Dominik Leiner for providing the SoSci Survey software, server, support, and the SoSci Panel for scientific research. The funders had no role in the study design, data collection, analysis, decision to publish, or preparation of the manuscript. The present work was performed in partial fulfillment of the requirements for obtaining the degree "Dr. med."

Conflict of interest None of the authors had a financial or personal conflict of interest.

\section{References}

Aboujaoude E, Koran LM, Gamel N, Large MD, Serpe RT (2006) Potential markers for problematic internet use: a telephone survey of 2,513 adults. CNS Spectr 11:750-755

Akobeng AK (2007) Understanding diagnostic tests 3: receiver operating characteristic curves. Acta paediatrica 96:644-647. doi:10.1111/j.1651-2227.2006.00178.x

Andreassen CS, Griffiths MD, Gjertsen SR, Krossbakken E, Kvam S, Pallesen S (2013) The relationship between behavioral addictions and the five-factor model of personality. J Behav Addict 2:90-99

Andreassen CS, Pallesen S (2014) Social network site addiction-an overview. Curr Pharm Des 20:4053-4061

Andreassen CS, Torsheim T, Brunborg GS, Pallesen S (2012) Development of a Facebook Addiction Scale. Psychol Rep 110:501-517

American Psychiatric Association (2013) Diagnostic and statistical manual of mental disorders (5th edn). Washington

Bakken IJ, Wenzel HG, Götestam KG, Johansson A, Øren A (2009) Internet addiction among Norwegian adults: a stratified probability sample study. Scand J Psychol 50:121-127. doi:10.1111/j. 1467-9450.2008.00685.x

Batthyàny D, Müller KW, Benker F, Wölfling K (2009) Computer game playing: clinical characteristics of dependence and abuse among adolescents. Wien Klin Wochenschr 121:502-509. doi:10.1007/s00508-009-1198-3

Büsch D, Hagemann N, Bender N. (2009) Das Lateral Preference Inventory: Itemhomogenität der deutschen Version. Zeitschrift für Sportpsychologie 16

Carli V et al (2013) The association between pathological internet use and comorbid psychopathology: a systematic review. Psychopathology 46:1-13. doi:10.1159/000337971

Cohen-Bendahan CCC, van de Beek C, Berenbaum SA (2005) Prenatal sex hormone effects on child and adult sex-typed behavior: methods and findings. Neurosci Biobehav Rev 29:353-384. doi:10.1016/j.neubiorev.2004.11.004

Conover WJ, Iman RL (1981) Rank transformations as a bridge between parametric and nonparametric statistics. Am Stat 35:12-129

Coren S (1993) The lateral preference inventory for measurement of handedness, footedness, eyedness, and earedness: norms for young adults. Bull Psychon Soc 31:1-3

Denny K (2011) Handedness and drinking behaviour. Br J Health Psychol 16:386-395. doi:10.1348/135910710X515705

Durkee T et al. (2012) Prevalence of pathological internet use among adolescents in Europe: demographic and social factors. Addiction 107:2210-2222. doi:10.1111/j.1360-0443.2012.03946.x

Dworak M, Schierl T, Bruns T, Strüder HK (2007) Impact of singular excessive computer game and television exposure on sleep patterns and memory performance of school-aged children. Pediatrics 120:978-985. doi:10.1542/peds.2007-0476 
Elias LJ, Bryden MP, Bulman-Fleming MB (1998) Footedness is a better predictor than is handedness of emotional lateralization. Neuropsychologia 36:37-43

Ewing JA (1984) Detecting alcoholism. The CAGE questionnaire. JAMA 252:1905-1907

Geschwind N, Galaburda AM (1985) Cerebral lateralization. Biological mechanisms, associations, and pathology: III. A hypothesis and a program for research. Arch Neurol 42:634-654

Griffiths M (2005) A 'components' model of addiction within a biopsychosocial framework. J Subst Use 10:191-197

Güntürkün O (2003) Human behaviour: adult persistence of headturning asymmetry. Nature 421:711. doi:10.1038/421711a

Gürtler D, Rumpf HJ, Bischof A, Kastirke N, Petersen KU, John U, Meyer C (2014) Assessment of problematic internet use by the compulsive internet use scale and the internet addiction test: a sample of problematic and pathological gamblers. Eur Addict Res 20:75-81. doi:10.1159/000355076

Harburg E (1981) Handedness and drinking-smoking types. Percept Mot Skills 52:279-282

Heinen T, Jeraj D, Vinken MP, Velentzas K. (2012) Rotational Preference in Gymnastics. J Hum Kinet 33

Holden C (2010) Psychiatry. Behavioral addictions debut in proposed DSM-V. Science 327:935. doi:10.1126/science.327.5968.935

Ko CH, Yen JY, Yen CF, Chen CS, Chen CC (2012) The association between internet addiction and psychiatric disorder: a review of the literature. Eur Psychiatry 27:1-8. doi:10.1016/j.eurpsy.04. 011

Kornhuber $\mathbf{J}$ et al (2011) Low digit ratio 2D:4D in alcohol dependent patients. PLoS One 6:e19332. doi:10.1371/journal.pone.0019332

Kornhuber J et al (2013) Low 2D:4D values are associated with video game addiction. PLoS One 8:e79539. doi:10.1371/journal.pone. 0079539

Kuss DJ, Griffiths MD (2011) Online social networking and addiction-a review of the psychological literature. Int J Environ Res Public Health 8:3528-3552. doi:10.3390/ijerph8093528

Leiner D (2014) Convenience Samples from Online Respondent Pools: A case study of the SoSci Panel. Working Paper. https:// www.researchgate.net/publication/ 259669050

Lejuez CW, Magidson JF, Mitchell SH, Sinha R, Stevens MC, de Wit $\mathrm{H}$ (2010) Behavioral and biological indicators of impulsivity in the development of alcohol use, problems, and disorders. Alcohol Clin Exp Res 34:1334-1345. doi:10.1111/j.1530-0277. 2010.01217.x

Lemmens JS, Valkenburg PM, Peter J (2011) The effects of pathological gaming on aggressive behavior. J Youth Adolesc 40:38-47. doi:10.1007/s10964-010-9558-x

Lenz B et al (2012) Sex hormone activity in alcohol addiction: integrating organizational and activational effects. Prog Neurobiol 96:136-163. doi:10.1016/j.pneurobio.2011.11.001

London WP, Kibbee P, Holt L (1985) Handedness and alcoholism. J Nerv Ment Dis 173:570-572

McNamara P, Blum D, O'Quin K, Schachter S (1994) Markers of cerebral lateralization and alcoholism. Percept Mot Skills 79:1435-1440

Meerkerk GJ, Van Den Eijnden RJJM, Vermulst AA, Garretsen HFL (2009) The Compulsive Internet Use Scale (CIUS): some psychometric properties. Cyberpsychol Behav 12:1-6. doi:10. 1089/cpb.2008.0181

Miles WR (1928) Ocular dominance-method and results. Psychol Bull 25:155-156

Morahan-Martin J, Schumacher P (2000) Incidence and correlates of pathological internet use among college students. Comput Hum Behav 16:13-29

Morrison CM, Gore H (2010) The relationship between excessive Internet use and depression: a questionnaire-based study of 1,319 young people and adults. Psychopathology 43:121-126. doi:10. $1159 / 000277001$

Nasrallah HA, Keelor K, McCalley-Whitters M (1983) Laterality shift in alcoholic males. Biol Psychiatry 18:1065-1067

Petry NM et al (2014) An international consensus for assessing internet gaming disorder using the new DSM-5 approach. Addiction. doi:10.1111/add.12457

Potenza MN, de Wit H (2010) Control yourself: alcohol and impulsivity. Alcohol Clin Exp Res 34:1303-1305. doi:10.1111/ j.1530-0277.2010.01214.x

Preti A, Usai I, Pintus E, Sardu C, Petretto DR, Masala C (2012) Lefthandedness is statistically linked to lifetime experimentation with illicit drugs. Laterality 17:318-339. doi:10.1080/1357650X. 2011.575786

Rehbein F, Mössle T, Arnaud N, Rumpf HJ (2013) Video game and internet addiction. The current state of research. Nervenarzt 84:569-575. doi:10.1007/s00115-012-3721-4

Rumpf HJ et al (2013) Occurence of internet addiction in a general population sample: a latent class analysis. Eur Addict Res 20:159-166. doi:10.1159/000354321

Spada MM (2014) An overview of problematic internet use. Addict Behav 39:3-6. doi:10.1016/j.addbeh.2013.09.007

Sperling W, Biermann T, Bleich S, Galvin R, Maihöfner C, Kornhuber J, Reulbach U (2010) Non-right-handedness and free serum testosterone levels in detoxified patients with alcohol dependence. Alcohol Alcohol 45:237-240. doi:10.1093/alcalc/ agq014

Sperling W, Frank H, Martus P, Mader R, Barocka A, Walter H, Lesch M (2000) The concept of abnormal hemispheric organization in addiction research. Alcohol Alcohol 35:394-399

Sussman S, Lisha N, Griffiths M (2011) Prevalence of the addictions: a problem of the majority or the minority? Eval Health Prof 34:3-56. doi:10.1177/0163278710380124

Thomasius R, Sack PM, Strittmatter E, Kaess M (2014) Substancerelated and addictive disorders in the DSM-5. Zeitschrift fur Kinder- und Jugendpsychiatrie und Psychotherapie 42:115-120. doi:10.1024/1422-4917/a000278

Wacker J, Mueller EM, Stemmler G (2013) Prenatal testosterone and personality: increasing the specificity of trait assessment to detect consistent associations with digit ratio (2D:4D). J Res Personal 47:171-177. doi:10.1016/j.jrp.2012.10.007

Wartberg L, Petersen KU, Kammerl R, Rosenkranz M, Thomasius R (2014) Psychometric validation of a german version of the compulsive internet use scale. Cyberpsychol Behav Social Netw 17:99-103. doi:10.1089/cyber.2012.0689

Weinstein A, Lejoyeux M (2010) Internet addiction or excessive internet use. Am J Drug Alcohol Abuse 36:277-283. doi:10. 3109/00952990.2010.491880

Wenzel HG, Bakken IJ, Johansson A, Götestam KG, Øren A (2009) Excessive computer game playing among Norwegian adults: self-reported consequences of playing and association with mental health problems. Psychol Rep 105:1237-1247

Witelson SF (1985) The brain connection: the corpus callosum is larger in left-handers. Science 229:665-668

Wolniczak I et al (2013) Association between Facebook dependence and poor sleep quality: a study in a sample of undergraduate students in Peru. PLoS One 8:e59087. doi:10.1371/journal.pone. 0059087

Wu AMS, Cheung VI, Ku L, Hung EPW (2013) Psychological risk factors of addiction to social networking sites among Chinese smartphone users. J Behav Addictions 2:160-166

Young KS (1999) Internet addiction: symptoms, evaluation and treatment. In: Vande-Creek L, Jackson T, editors Innovations in Clinical Practice: A source Book 17:19-31 
Open Access This article is licensed under a Creative Commons Attribution 4.0 International License, which permits use, sharing, adaptation, distribution and reproduction in any medium or format, as long as you give appropriate credit to the original author(s) and the source, provide a link to the Creative Commons licence, and indicate if changes were made. The images or other third party material in this article are included in the article's Creative Commons licence, unless indicated otherwise in a credit line to the material. If material is not included in the article's Creative Commons licence and your intended use is not permitted by statutory regulation or exceeds the permitted use, you will need to obtain permission directly from the copyright holder. To view a copy of this licence, visit http://creativecommons.org/licenses/by/4.0/. 